\title{
Career Development of Educational Personnel: Exploratory and Confirmatory Factor Analysis
}

\author{
Rahmat Murbojono, Firman, Robin Pratama, Yusdi Anra \\ Faculty of Teacher Training and Science Education \\ Jambi University \\ Jambi, Indonesia \\ robin.pratama@gmail.com
}

\begin{abstract}
This study aimed to examine the validity of the instrument to determine the structure and explore factors in the variable indicators of career development. This is a survey design research. Statistical analysis was applied to explore the factor structure of Career Development for Educational Personnel at Jambi University. Using cluster random sampling, the respondents involved were 164 Education Personnel in Jambi University. The stages of this study aimed to examine the validity of the instrument with quantitative data analyzed using exploratory factor analysis (EFA) to determine the structure and explore factors in the variable indicators of Career Development. Confirmatory factor analysis (CFA) was carried out to verify the factorial validity of career development. The CFA can provide further evidence of the suitability of the suggested model by considering the structure of the factors identified through EFA. The findings of this research concluded that there are four factors in the structure of the career development of personnel education personnel at Jambi University. This finding suggests the importance of validating and confirming the structure of career development of education personnel towards translating constructs into different languages.
\end{abstract}

Keywords-career development; educational personnels; factor analysis

\section{INTRODUCTION}

Career development is intended in order to increase individual competitiveness in tight competition, both inside and outside the organization. Hence, it can be improved and can impact the progress of an institution or organization. More specifically, career development needs to be well planned and programmed in the right ways to guarantee the availability of employees with the right qualifications and experience for organizational improvement. In addition, in the process it can ideally provide certainty and assurance to employees in growing and developing all capabilities possessed by employees in terms of intellectuality, insight, motivation, and dedication to be able to carry out a mandated job position. Efforts to provide this guarantee can be achieved by fostering employees towards "the right man in the right place". An employee should be placed in a position according to his competency, because if the position is filled by individuals who are not right, it will have a negative impact on the organization.
There are some previous studies that discuss career advancement that have a significant role in career choice and performance [1], [2]. Many previous studies are important studies in analyzing factors in career development towards employee performance [3-5].

The difficulty of employees or educational staff of the Jambi University in developing their careers can be seen in the appointment of educational staff in structural positions. In reality, the appointment of educational staff in structural positions (level IIIa to level IIId and level IVa to level IVd) has not taken into account of competency factors, education, job training, and tenure. Additionally, the appointment of structural positions has not been based on an assessment of working weight, authority, and responsibility.

Other issues also arise in managing promotions from group IIId to IVa and especially from groups IVa to IVb and so forth. In the new promotion rules, it is clearly stated that educational personnel who will rise to rank from Group III/d to IV/a should carry out self-development activities. It becomes one of the reasons why it is difficult for educational staff in university to develop their careers. The difficulty of educational staff for promotion can be seen in the data on the employees personal data (DUK) of educational staff available in Jambi University.

Weng, McElroy, Morrow \& Liu [6] stated that there are four factors in employee career growth, namely; advancement of career goals, development of professional abilities, speed of promotion, and growth of remuneration. This career development dimension shows that employee career growth is an employee's progress towards their career goals and gaining new skills as an organization's effort to reward employees through promotions and salary increases. The research questions can be summarized as follow, what is the structure of the four factors related to the Career Development of Educational Personnels instrument optimally in accordance with the data in the context of Jambi University? what is the Career Development of Educational Personnels instrument reliable and valid for measuring the intention of student entrepreneurship in the context of Jambi University?

Career development is a personal improvement effort by an employee to achieve goals and increase career in an organization by related parties to achieve a career plan in accordance with the path or level of existing organization in 
an organization. It generally starts with evaluating the performance. The benefits of career development are to improve the ability of employees and increase the supply of capable employees [7].

Career growth is an opportunity for employees to be promoted and gain career development experience, remuneration, enhanced responsibilities and professional abilities in an organization [6]. Perception of career growth is the possibility felt by staff or employees related to the development and progress of their careers in an organization, the possibility consists of four factors, namely, the goal of career development, professional capacity development, speed of promotion, and remuneration growth [6]. Therefore, career development is an increase in the status of a person in the organization in the specified career path. To achieve this goal, of course, an employee needs to improve his professional performance [8].

Besides, Gayani [9] considers that the career development of each individual is a working experience throughout one's life divided into several stages starting from the initial intention to work and ending with retirement. This statement recognizes that each person's career stages is carried out from childhood to maturity by considering various factors such as mental abilities, physical abilities, individual characteristics, and other opportunities to contribute an individual's career [10]. Therefore, individual career development consists of several stages such growth, exploration, formation, maintenance or management, and setback [11].

Gottfredson [12] then developed a career development theory based on the theory proposed by Super and Holland. Gottfredson [12] through the theory of "boundaries and compromise" assumes that career choice is a high level of cognitive proficiency which is a unitary process. Cognitive growth and development is a tool for developing a cognitive map of position and self-conception used to evaluate the suitability of various alternative positions. Gottfredson [12] sees a link between genetic factors and the environment. Genetic characteristics play an important role in shaping the basic characteristics of individuals such as interests, skills, and values. The basic characteristics then will be affected by the environment in which the individual career [11].

The starting point of career development starts with employees. Each employee is responsible for progress development of his career. After strong personal commitment, several development activities are carried out including working performance, exposure, quit requests, organizational loyalty, mentors and sponsors, and opportunities to grow. The most important activity to advance careers is good working performance because this underlies career development and progress. Career development is also determined by exposure which is becoming recognized by people who decide on promotions, transfers, and other career opportunities. If an employee sees progress or better career development elsewhere, then he can submit a stop request as a way to achieve career goals. Additionally, organizational loyalty also determines career progress and development. Low organizational loyalty is generally found in new scholars and professionals. Moreover, mentors and sponsors are also important to determine the organizational development. A mentor is a person who offers informal career guidance while sponsors are people in organizations who can create career development opportunities for others. Finally, if employees improve their abilities through training, courses, and further education, it means that they have taken advantage of opportunities to grow [7].

From the theories previously presented, career development is defined as a process of improving personal quality to reach a certain career path in accordance with the stages of career planning that have been determined. Several indicators of career development are satisfactory achievement, recognizing each others, loyal to the organization, utilization of trainers, peer support, and opportunity to develop.

\section{METHOD}

Cross-sectional survey research design [13-15] is a procedure in quantitative research that provides an opportunity to manage surveys for samples or the entire population to describe attitudes, opinions, behaviors or characteristics of the population at one time. The current research population consists of employees at Jambi University. Participants were 164 education staffs. This research used is conducted cluster random sampling technique by selecting individuals in groups [16].

This research began by translating the original questionnaire into Indonesian before the question items were used to test the validity and reliability. The results of the translation of the questionnaire into Indonesian were consulted with four bilingual linguists. This variable measurement is carried out using the four dimensions of career development proposed by Weng et al [6]. The career development dimension consists of four sub-constructions which are classified into career goal progress (CGP), professional ability development (PAD), promotion speed (PS), remuneration growth (RG). Each sub-construct has two to four item statements, the questionnaire consists of 13 questions measured on a Likert scale with a seven-point scale ranging from 1 (strongly disagree) to 7 (strongly agree).

The stages of this study aim to examine instrument validity with quantitative data analyzed using exploratory factor analysis (EFA). The EFA was carried out to determine the structure and explore the factors in the $\mathrm{CD}$ variable question indicator. Because this study uses an existing scale that was originally developed in China, it is important to purify the scales and check their validity. EFA as an analysis is used to explore how many factors can be used, whether these factors are correlated and the observed variables seem to best measure each single factor [17]. This study identified the value of Kaiser Meyer Olkin (KMO), Bartlett's value, loading factor, eigen value, scree plot, and rotation of Oblimin with Kaiser Normalization. The KMO index is located between 0 and 1, with a value of more than 0.50 considered appropriate for factor analysis [18], while a score of more than 0.80 is considered very satisfactory [19]. Bartlett's Test of Sphericity is significant $(\mathrm{p}<0.05)$. For Hair et al [20], the overall value of factor loading for each item above 0.50 is significant to confirm the meaningfulness of the questionnaire. The 
eigenvalues and scree plots also show the proportion of the contribution of variance extracted by each factor through factor analysis [18], where factors with eigenvalues lower than 1.0 are removed from the list of factors. Outliers are identified by the plot box for each sub-construction. Furthermore, the data in this study also were analyzed by Confirmatory Factor Analysis (CFA) using AMOS 23.0 was applied to the first order. Brown (2014) indicated that goodness of fit was evaluated by employing chi-square $(\chi 2)(\mathrm{P}>0.05)$, Comparative Fit Index (CFI > 0.90), Tucker Lewis Index (TLI $>0.90)$ and Root Mean-Square Error of Approximation (RMSEA < 0.08).

\section{RESUlTS AND DISCUSSION}

\section{A. Exploratory Factor Analysis (EFA)}

The construct of Career Development (CD) variable is measured by a scale adapted from Weng et al [6]. Exploratory factor analysis (EFA) was used to establish constructs and convergent validity using principal component analysis techniques with the Oblimin rotation method as shown in Table 2. The statistical criteria in this study were fulfilling criteria (satisfactory). The KMO value for SBM is $0.718>0.60$ (see Table 1), which provides information about the availability of sufficient items for each factor analyzed $(n=164)$. In addition, the value of Bartlett's Test of Sphericity results showed that the score that appeared statistically was significant $[\chi 2=2145,654 ; p<0,000]$. Thus, the use of factor analysis is acceptable for the data collected in this study.

TABLE I. ASSUMPTIONS OF FACTOR ANALYSIS

\begin{tabular}{|l|l|}
\hline \multicolumn{1}{|c|}{ EFA's assumptions } & Value (CD) \\
\hline $\begin{array}{l}\text { Kaiser-Meyer-Olkin Measure of Sampling } \\
\text { Adequacy }\end{array}$ & 0,718 \\
Bartlett's Test of Sphericity (Approx. Chi- & 2145,654 \\
Square) & \\
Bartlett's Test of Sphericity (Sig) & 0,000 \\
\hline
\end{tabular}

EFA begins by considering all 15 items that measure the four dimensions of CD. Every aspect of dimensions is measured by several items. The next step is to identify the values of extraction communalities, eigenvalues, percentage of variances and factor loading. Table 2 . presents detailed values of the extraction communalities, eigenvalues, percentage of variances and factor loading explained by the four subconstructions of CD. First, the communal values of extraction represent the variance in each item calculated before and after factor analysis. The values of communalities for each item less than 0.50 were aborted from further analysis [20]. A small value $(<0.50)$ of values of the extraction communalities shows that all values of the extraction communalities items range from 0.581 to 0.923 which exceeds the level of 0.50 , meaning the values of the extraction communalities described are sufficient. Components of oblimin after-rotation matrix are used to identify items that are more related to each factor. In this study (13 items) in the matrix pattern it is recommended to measure Career Development because it fulfills the criteria by a fairly high loading factor with values ranging from 0,775 to $0.964(>0.50)$.
TABLE II. FACTOR ANALYSIS OF THE CAREER DEVELOPMENT OF MODIfIED FOR USE WITH EDUCATIONAL PERSONALS (COMPONENTS PATTERN MATRIX WITH ROTATION METHOD: OBLIMIN WITH KAISER NORMALIZATION)

\begin{tabular}{|c|c|c|c|c|c|}
\hline & & \multicolumn{4}{|c|}{ Component } \\
\cline { 3 - 6 } Items & Communalities & $\begin{array}{c}\text { Factor } \\
\mathbf{1}\end{array}$ & $\begin{array}{c}\text { Factor } \\
\mathbf{2}\end{array}$ & $\begin{array}{c}\text { Factor } \\
\mathbf{3}\end{array}$ & $\begin{array}{c}\text { Factor } \\
\mathbf{4}\end{array}$ \\
\hline PAD4 & .944 & .961 & & & \\
\hline PAD2 & .924 & .955 & & & \\
\hline PAD1 & .681 & .844 & & & \\
\hline PAD3 & .646 & .775 & & & \\
\hline CGP2 & .919 & & .960 & & \\
\hline CGP3 & .881 & & .937 & & \\
\hline CGP4 & .823 & & .908 & & \\
\hline CGP1 & .737 & & .857 & & \\
\hline PS3 & .944 & & & .964 & \\
\hline PS4 & .918 & & & .957 & \\
\hline PS2 & .827 & & & .909 & \\
\hline RG2 & .846 & & & & .933 \\
\hline RG3 & .812 & & & & .872 \\
\hline
\end{tabular}

Another method for selecting the number of correct factors to extract is to investigate the scree of the plot (Figure 1). As shown in Figure 1, the scree plot shows four factors that can be determined eigenvalue $(>1)$. For eigenvalue; $\mathrm{CGP}=3,880$; $\mathrm{PAD}=3,150 ; \quad \mathrm{PS}=2,554 ; \quad \mathrm{RG}=1,318$. For $\%$ Variance; $\mathrm{CGP}=29,85 \%$; $\mathrm{PAD}=24,23 \% ; \mathrm{PS}=19,64 \% ; \mathrm{RG}=10,13 \%$.

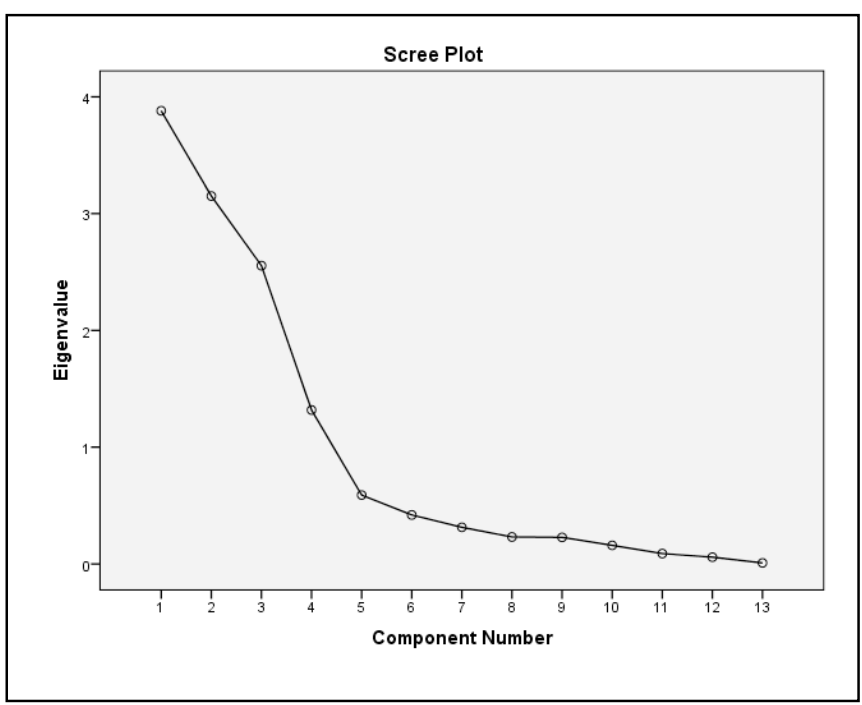

Fig. 1. Scree Plot (eigenvalue $>1$ )

\section{B. Confirmatory Factor Analysis (CFA): Testing the Measurement Models}

In this study, EFA suggested a four-factor structure for constructing variable Career Development (CD), namely career goal progress (CGP), professional ability development (PAD), promotion speed (PS), remuneration growth (RG). CFA is carried out to verify the factorial validity of $\mathrm{CD}$. The CFA can provide further evidence of the suitability of the suggested models by taking into account the structure of the factors identified through EFA. The results of the models analyzed will be compared using chi-square $(\chi 2)$, CFI, TLI and RMSEA. 
The model specifications for the post hoc CFA. The CFA results for the four-factor model hypothesized are very good. The factor structure reaches an acceptable model that is suitable for the research context (Jambi University). The measurement model of CD in this Study shows an acceptable model fit, $\chi 2=90,909, \chi^{2} / \mathrm{df}=1,567$, RMSEA $=0.059$, TLI $=0.979$ and $\mathrm{CFI}=0.985$. Therefore, the CFA model presented in Figure 2. is a final measurement model that shows the structure of $\mathrm{CD}$ in the context of the research location.

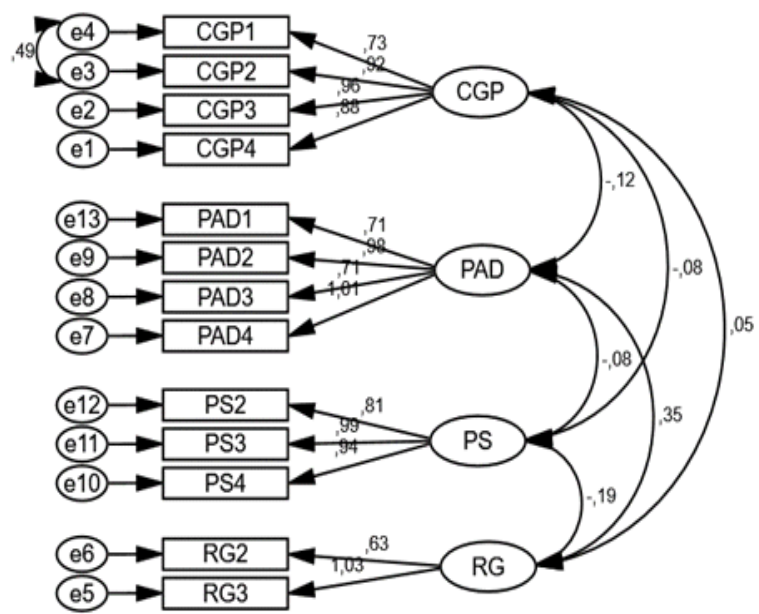

Fig. 2. The final model of CFA measurement

Figure 2. illustrates that the measurement model of $\mathrm{CD}$ between observed variables and latent variables uses the AMOS 23.0 program. All factors contain four sub-constructs of Entrepreneurial Intention (EI) ranging from 0.73 to 1.00 . The results show that Factor Loadings exceed the desired standard 0.50 [20], which shows the power of acceptance of the convergent validity test. In addition, the correlation between the four CD sub-constructs ranged from 0.05 to 0.35 , which indicates acceptable discriminant validity.

\section{CONCLUSION}

This study has used ideal research methods to present some of the most important empirical data in placing validity in the proposed CD dimension. This instrument has developed a measure of $\mathrm{CD}$ that is validated in the context of research, namely educational personnel. There is little empirical research conducted to develop a measure of $\mathrm{CD}$. This article carries a number of research implications and directions for academics and practitioners to investigate $\mathrm{CD}$ among educational personnel. The specified framework offers a thorough understanding of the nature and intricacies of CD. Overall, exploratory factor analysis and confirmation indicate that the scale of career development has four constructs and needs to be used carefully. By removing RG1 and PS1 items by loading the lowest factor, it is suitable to balance the 15item version obtained.

Construct validity is an important step for the development of a scientific questionnaire measurement scale. The construct validity basically increases over time and through many previous studies. This scale requires further adjustments to increase the level of reliability and ability to explain the variance associated with construction measured in different contexts, cultures and conditions. Future research is recommended to be examined, with randomly selected samples, generalization and model validity. It is also proposed to validate cross instruments in different cultures with various methods that include the habitual context, focus group discussions with interviews with peers and face to face.

\section{REFERENCES}

[1] Z. Aycan and S. Fikret-Pasa, "Career choices, job selection criteria, and leadership preferences in a transitional nation: The case of Turkey," Journal of Career Development, vol. 30, pp. 129-144, 2003.

[2] N.-K. Chuang and M. Dellmann-Jenkins, "Career decision making and intention: A study of hospitality undergraduate students," Journal of Hospitality \& Tourism Research, vol. 34, pp. 512-530, 2010.

[3] D. L. Choi, "Development of a diagnosis model for pay-forperformance in the public sector and its application: Focused on agencies," International Review of Public Administration, vol. 11, pp. 29-41, 2006.

[4] M. Y. Kim, H. J. Yu, and S. M. Park, "Examining and testing the roles of human resource development (HRD) in the public sector: evidence from US federal agencies," International Review of Public Administration, vol. 22, pp. 60-86, 2017.

[5] J. W. Lee, Y. J. Cho, and S. E. Kim, "Improving performance: Does performance-oriented management really matter?," International Review of Public Administration, vol. 13, pp. 17-34, 2009.

[6] Q. Weng, J. C. McElroy, P. C. Morrow, and R. Liu, "The relationship between career growth and organizational commitment," Journal of Vocational Behavior, vol. 77, pp. 391-400, 2010.

[7] Sunyoto, Manajemen sumber daya manusia. Yogyakarta: CAPS, 2013.

[8] S. Napitupulu, T. Haryono, A. L. Riani, S. R. Sawitri, and M. Harsono, "The impact of career development on employee performance: an empirical study of the public sector in Indonesia," International Review of Public Administration, vol. 22, pp. 276-299, 2017.

[9] D. N. Elvitigalage, R. Amaratunga, and R. Haigh, "The impact of culture on career development of women in construction," in 6th International Postgraduate Research Conference in the Built and Human Environment, United Kingdom, 2006.

[10] A. Osibanjo, A. Omotayo, E. Oyewunmi, and I. S. Ojo, "Career development as a determinant of organizational growth: Modelling the relationship between these constructs in the Nigerian banking industry," American International Journal of Social Sciences, vol. 3, pp. 67-76, 2014.

[11] J. A. Athanasou and R. V. Esbroeck, An international and social perspective on career guidance. Dordrecht: Springer, 2008.

[12] L. S. Gottfredson, "Using Gottfredson's theory of circumscription and compromise in career guidance and counseling," Career development and counseling: Putting theory and research to work, pp. 71-100, 2005.

[13] L. Cohen, L. Manion, and K. Morrison, Research methods in education: routledge, 2002.

[14] J. W. Creswell, Qualitative inquiry and research design: Choosing among five approaches: Sage publications, 2012.

[15] J. D. Schenker and P. D. Rumrill Jr, "Causal-comparative research designs," Journal of vocational rehabilitation, vol. 21, pp. 117-121, 2004.

[16] J. R. Fraenkel, N. E. Wallen, and H. H. Hyun, How to design and evaluate research in education: New York: McGraw-Hill Humanities/Social Sciences/Languages, 2011.

[17] R. E. Schumacker and R. G. Lomax, "A Beginner's Guide to," Structural Equation Modeling (3rd Edition), New York: Taylor \& Francis Group, 2010. 
[18] Y. P. Chua, Ujian regresi, analisis faktor dan analisis SEM Malaysia: McGraw-Hill Education, 2014.

[19] M. T. Frohlich and R. Westbrook, "Arcs of integration: an international study of supply chain strategies," Journal of operations management, vol. 19, pp. 185-200, 2001.
[20] J. F. Hair, W. C. Black, B. J. Babin, R. E. Anderson, and R. L. Tatham, "Multivariate data analysis 6th Edition. Pearson Prentice Hall. New Jersey. humans: Critique and reformulation," Journal of Abnormal Psychology, vol. 87, pp. 49-74, 2006. 